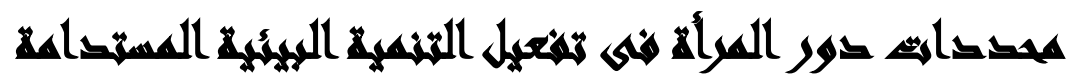 بهماهظكلة المنيا
}

\section{[1 \{]}

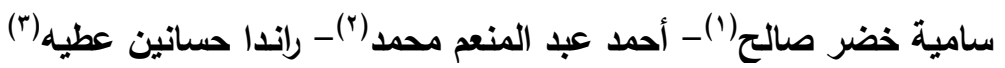

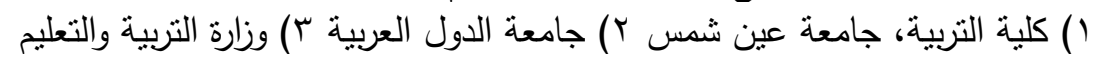

\section{المستخلصى}

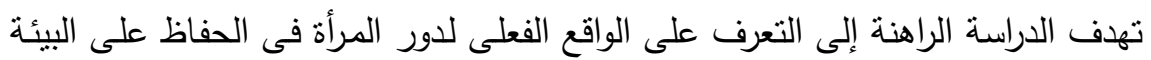

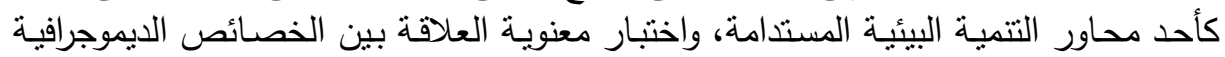

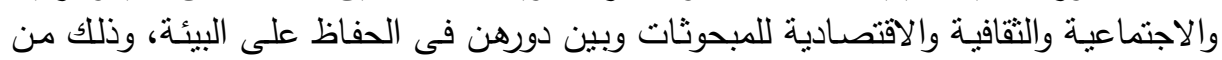

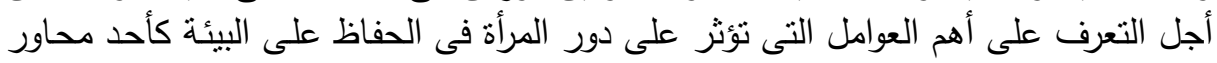
التتمية البيئية المستدامة.

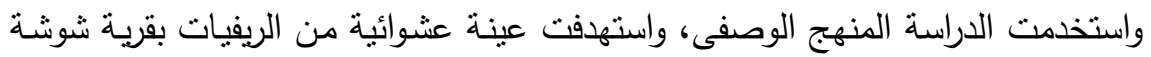

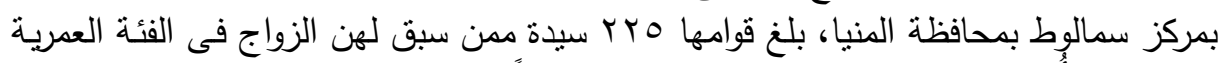

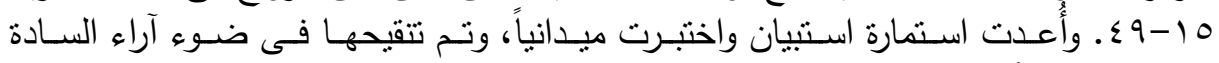

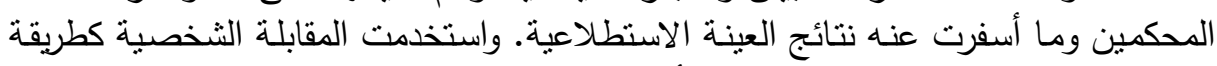

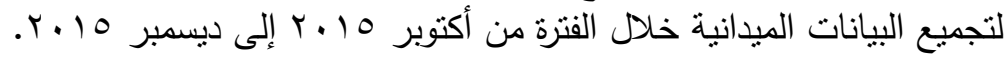

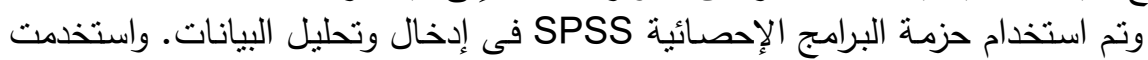

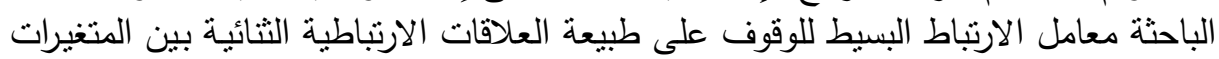

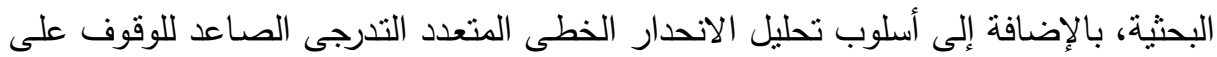

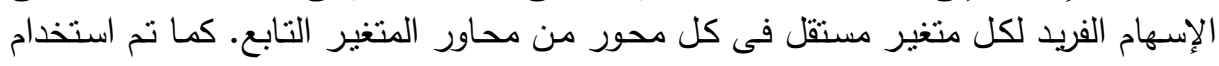
اختبار "ف" لاختبار معنوية النماذج التحليلية.

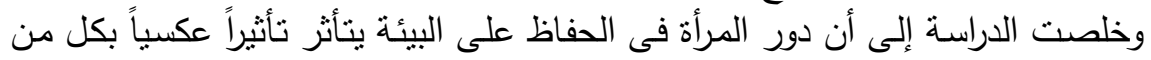

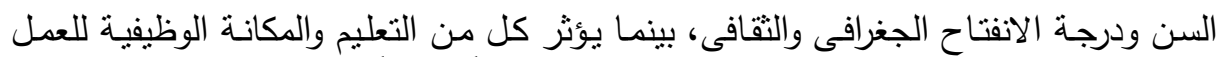

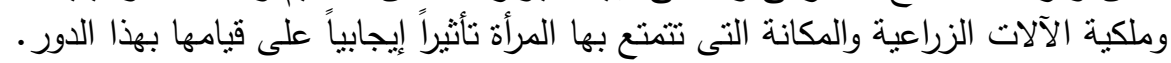

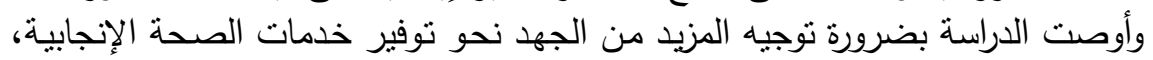

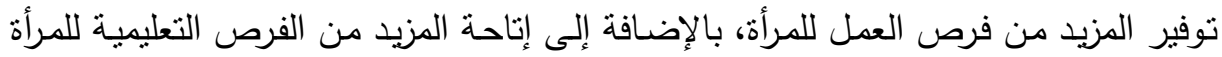

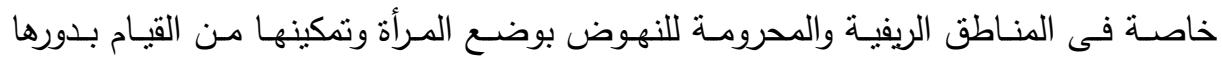
المأمول فى الحفاظ على البيئة كأحد المحاور الأساسية لتحقيق التتمية البيئية المستدامة.

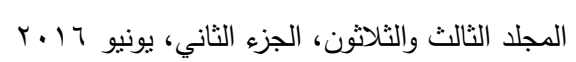




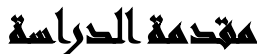

تُعتبر التتمية المستدامة من أهم التطورات فى الفكر التتموى الحديث، وأبرز إضـافة إلى أدبيات التتمية خـلال العقود الأخيرة، بحيث ارتبطت هذه الظـاهرة بتزايد الوعى إزاء المشـاكل البيئية والعلاقة القائمة بين الإنسان والتتمية والبيئة. (إلهام شيليى، ـ ا ـ ؟: ص (T) والتتميـة المستدامة هى نسـق اجتمـاعى بيئى اقتصـادى شـامل يدعو إلى تمكين المرأة

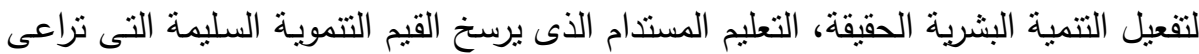

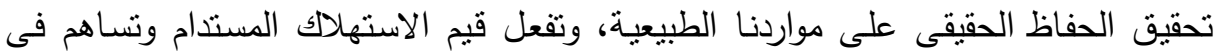
حماية قطرة المياه، وأيضاً الطاقة، وما إلى آخره من مفاهيم تتموية مستدامة. ويُعد تطبيق التتمية المستدامة السبيل الوحيد الصعب والسهل فى آن واحد لتحقيق العدالة الاجتماعية ليس فقط للشعوب التى تحيا حالياً، بل للأجيال القادمة. وتمنل التتمية الريفية المستدامة إحدى الاتجاهات الهامة فى التتمية الزراعية خاصة بعد

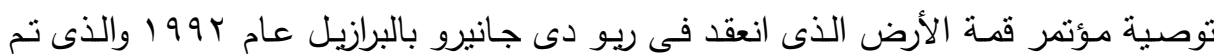

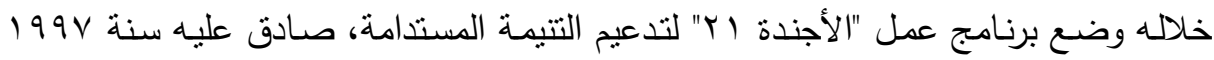
أكثر من 170 دولة. ثم جاءت قمة التتمية المستدامة فى جوهانسبرج فى جنوب أفريقيا سنة

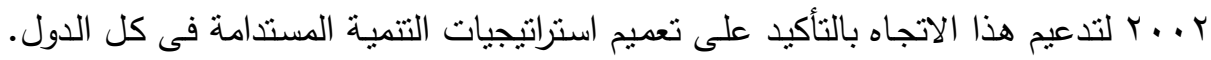

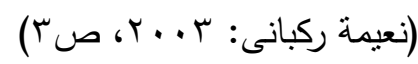

ولا شـك أن قضية البيئة عامـة والبيئة الريفيـة خاصـة وحمايتها مـن كافـة أنواع التلوث واحدة من أهم قضايا العصر وتحدياً خطيراً أمام تحقيق التتمية المستدامة، مما ينعكس أثثره

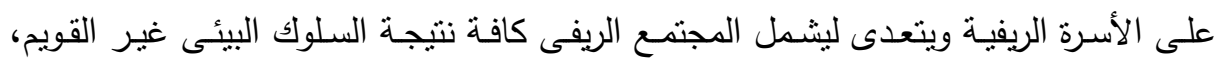

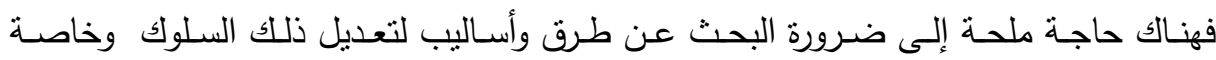
الممارسات البيئية للمرأة الريفية والتىى هى الهدف من الدراسة الحالية وكيفية التعامل مع البيئة

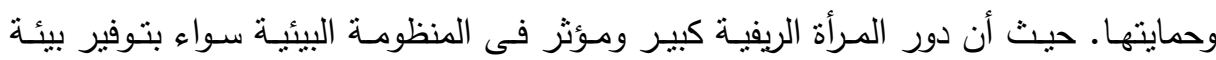

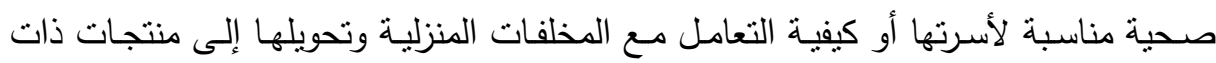
قيمة اقتصادية تعود بالنفع على البيئة بالتخلص من المخلفات باستخدامها فى مجالات أخرى لهاته 
وأيضاً تعود بالنفع على أسرتها بتحقيق ربح اقتصادى وفقاً للمستوى المعرفى والتقنى المتوفر

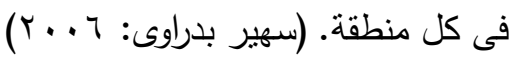

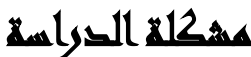

يتكـون أى مجتمـع مـن المجتمعـات مـن نصـفين منمـاتلين تقريبـاً: الرجلـل والمـرأة، ومـن الطبيعى يجب استغلال كافة الطاقات الممكنة وتطويعها فى خدمة المجتمع وتطويره. إذ أن إغفال المرأة وهى تمثل نصف طاقة المجتمع لا يؤدى إلى حرمان الأمـة من جهود نصف

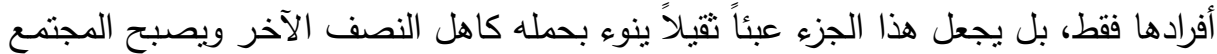

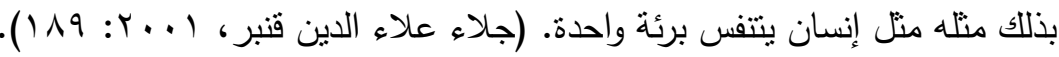

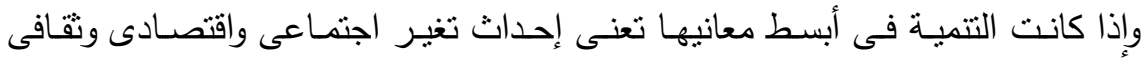
مخطط ومقصود لرفع مستوى المعيشة، وذللك عن طريق تعبئة كافة الجهود البشرية لتحقيق إنق الأهداف المرجوة بأعلى كفاءة ممكنة، وبأقل هدر للإمكانيات وفى أقصر وقت، فإن هذا يستلزم بالضرورة تغيير النظرة التقليدية نحو المرأة، وإتاحة الفرصة لها للمشـاركة الفاعلة فى لهى جهود التتمية. فالمرأة تمثل نصف المجتمع ونصف طاقته الإنتاجية، ومن هنا كان تمكينها من

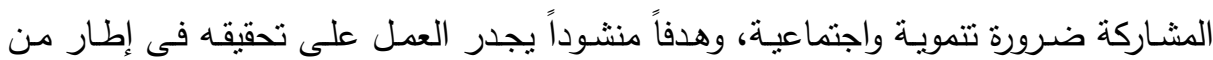

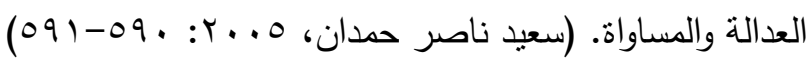

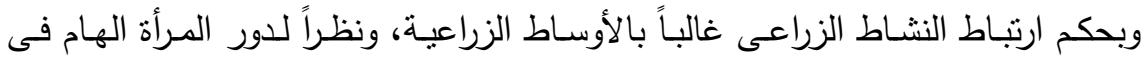

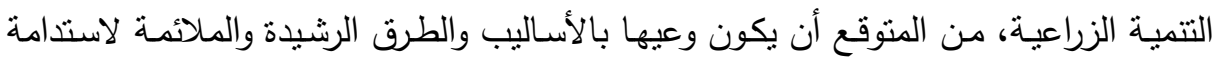

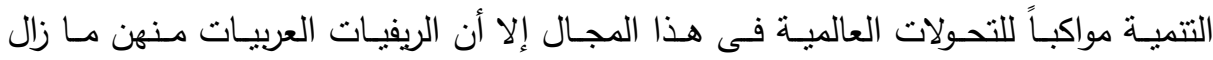
ينقصهن الكثير لنطوير وعيهن البيئى حيث ما زلن يواجهن معوقات تحول دون لإطلاعهن على ما يستجد من معلومات وإيضاحات حول النشاط البيئى وكيفية تحقيق تتمية مستدامة.

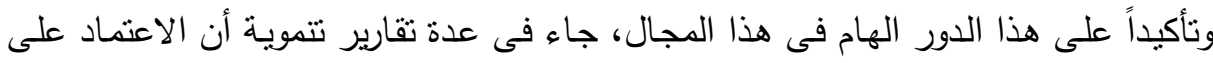

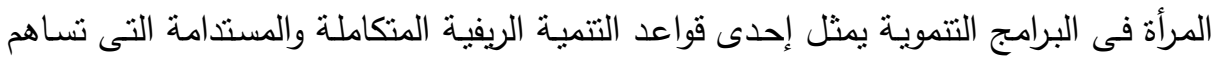

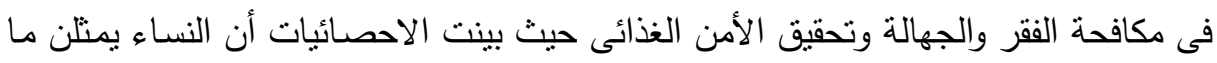

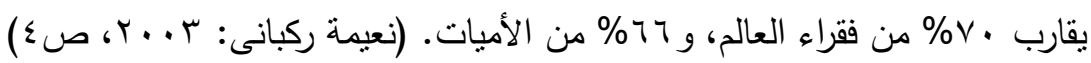

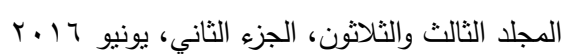


وفى نفس السياق أكد تقرير التتمية الإنسانية العربية لعام 9 . . ب أن تمكين المرأة يمثل إحدى النواقص فى البنية المؤسسية التى من شأنها أن تعوق بناء التتمية الإنسانية، وأن التتمية التهبية

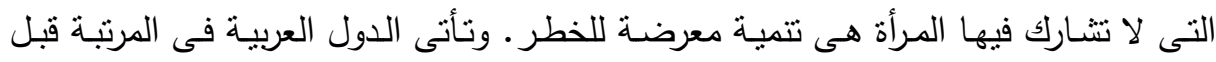

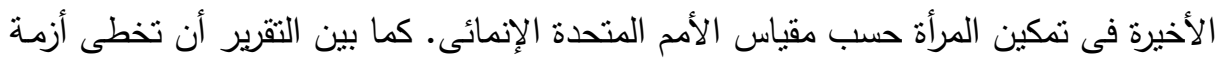

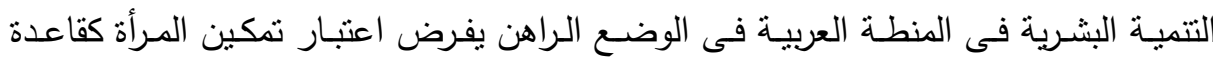

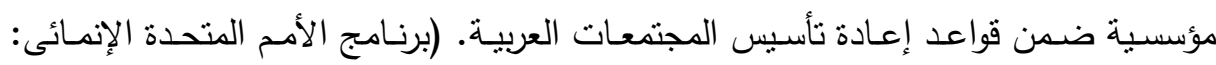

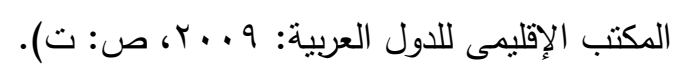

وفى دراسة أجرتها هبة عبد الحميد على عينة من الريفيات بقربتين من قرى محافظة

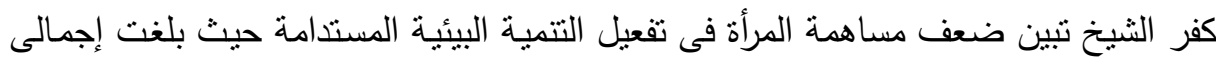

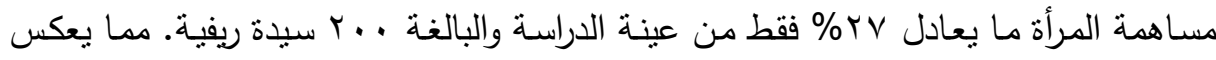

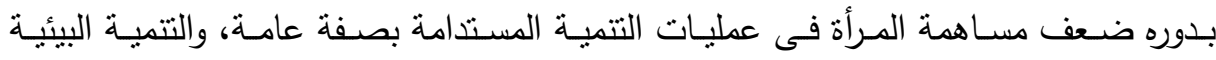
المستدامة بصفة خاصة وهو ما يمثل بدوره عائق نحو تحقيق التتمية المستدامة.

\section{تساؤلايت السراهم}

تهدف الدارسة الحالية إلى الإجابة على سؤال رئيس وهو: ما الدور الذى تقوم به المرأة فى

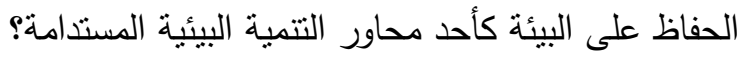
وينبثق من هذا السؤال الرئيس سؤالين فرعيين هما: () هل يختلف دور المرأة فى الحفاظ على البيئة باختلاف خصائصها الديموجرافية والاجتماعية والثقافية والاقتصادية؟ r) ما محددات دور المرأة فى الحفاظ على البيئة كأحد محاور التتمية البيئية المستدامة؟ والئه 


\section{هزوض الصراسلة}

تمشياً مع أهداف الدراسة الحالية، فقد نم صياغة الفروض البحثية التالية: () توجد فروق ذات دلالة إحصائية بين الخصائص الديموجرافية والاجتماعية والثقافية والاقتصادية للمرأة المتمثلة فى كل من: سن المبحوثة، تعليم المبحوثة، الدخل الثهرى

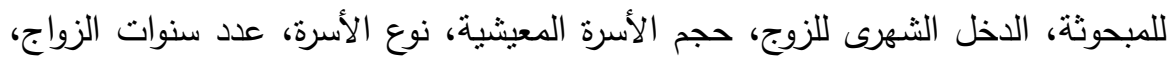

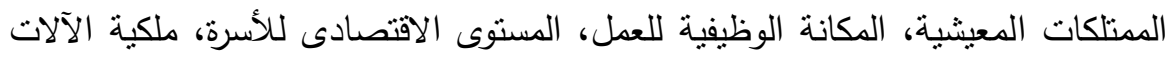

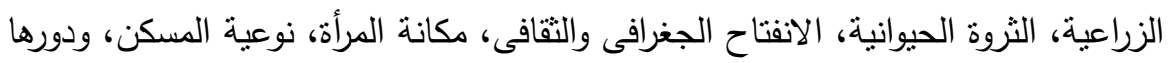

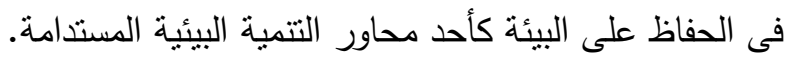
r) يسهم كل متغير من المتغيرات المستقلة التالية: سن المبحوثة، تعليم المبحوثة، الدخل

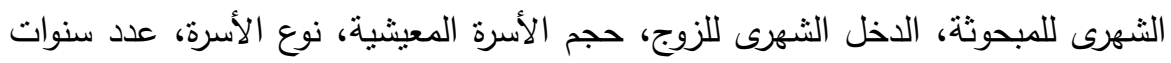

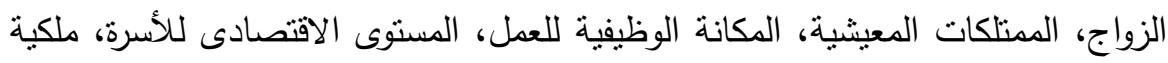

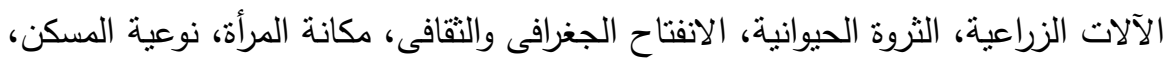

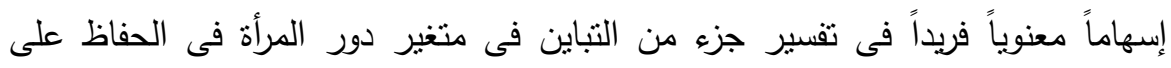
البيئة.

\section{الهساهيم التراسلة}

تهدف الدراسة الحالية إلى:

() الوقوف على محددات دور المرأة فى الحفاظ على البيئة كأحد محاور التنمية البيئية المستدامة.

r) التوصل لبعض الحلول والمقترحات التى تساعد على تفعيل دور المرأة فى التتمية البيئية المستدامة. 


\section{أهمية المهميه}

تأتى أهمية الدراسة الحالية من منطلق أن المرأة بحكم تعدد أدوارها فى المجتمع، كأم

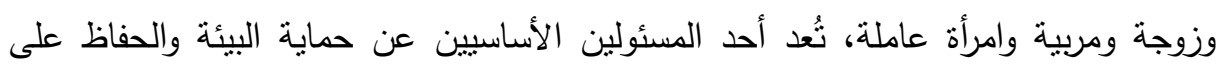

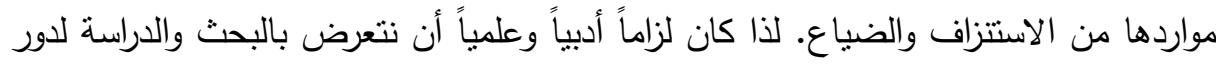

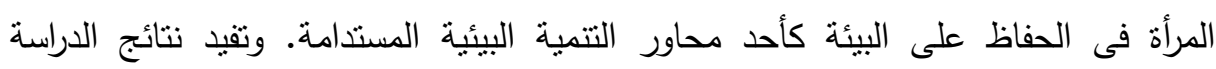
واضعى السياسات ومتخذى القرار والمهتمين بالمرأة بشكل عام وبدروها الفعال لتحقيق التتمية المستدامة بوجه خاص.

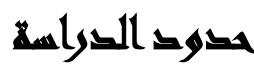

( ) الحد المكانى: قرية شوشة بمركز سمالوط بمحافظة المنيا: r) الحد البشرى: بلغ حجم إجمالى العينة هبr سيدة ممن سبق لهن الزواج وفى المرحلة العمرية 10-10 - (1) سنة.

ץ) الحد الزمانى: استغرقت الدراسة حوالى أربعة سنوات منها ثناث أثنهر للاراسة الميدانية

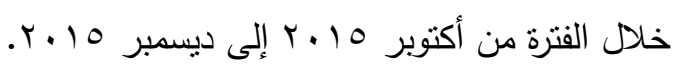

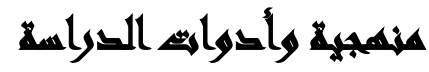

استخدمت الدراسة الحالية المنهج الوصفى التحليلى، ونم جمع البيانات عن طريق المقابلة الثخصية مع المبحوثات من منطقة البحث باستخدام استمارة استنيان ثم تصميمها

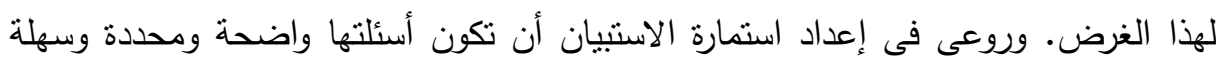
الفهم من جانب المبحوثات. واقتصرت عينة الدراسة على السيدات فى المرحلة العمرية من 10-9 ـ سنة ممن سبق لهن الزواج. 


\section{مهاسهيه السراسمة}

مفهوم الدور: يُعرف الدور بأنه "مجموعة من التوقعات لمعرفة السلوك المناسب من قبل شاغل وضع معين لوضع آخر" (Johnson D. \& Johnson F. P., 1991:17)

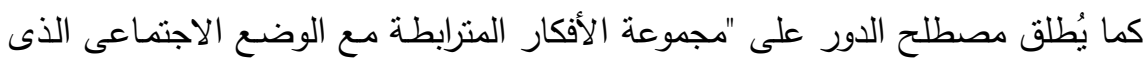

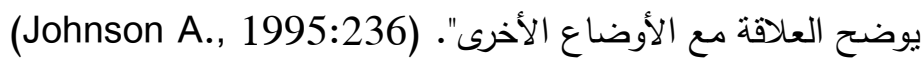
مفهوم دور المرأة فى التنمية: إذا كان مصطلح الدور يلخص الفعل الذى يتوقع أن يقوم

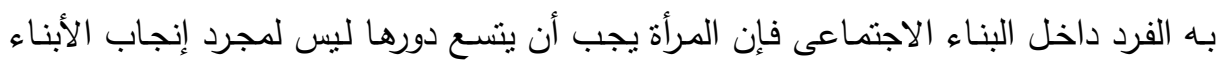

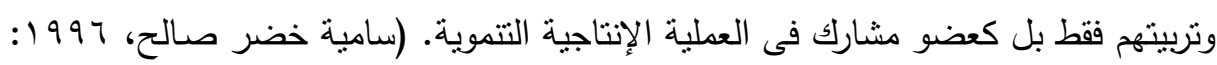

مفهوم البيئة: المحيط الذى يقطن فيه الإنسان وتتأثر به ظروفه الصحية والنفسية، فهى

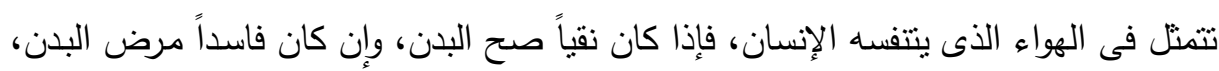
وهى أيضاً الماء الذى يشربه الإنسان ويغتسل به، والأرض التى ينشأ عليها ويتربى من خيراتها

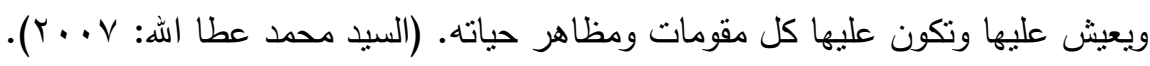
مفهوم التنمية المستدامة: تعريف لجنة برونتلاند 19 1 (اللجنـة العالمية للتنمية المستـامة):"هى التتمية التى تلبى

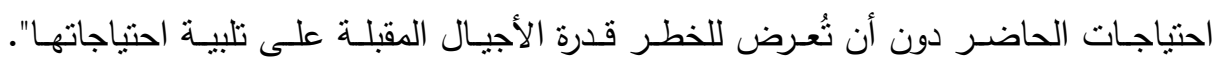
(WCED, 1987: 43)

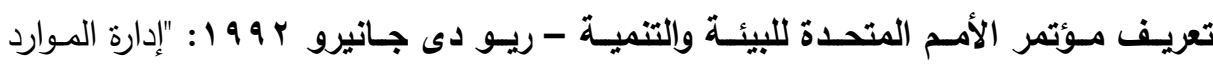

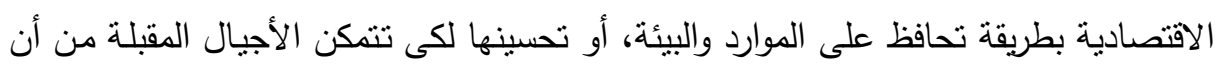
تعيش حياة كريمة أفضل".(UNED,1992)

\section{السراسايس الماريهان}

فى سبيل تحقيق أهداف الدراسـة الحالية، استعرضـت الباحثة مجموعـة مـن الدراسـات المرتبطة بموضوع الدراسة الحالية بغرض البدء من حيث انتهى الآخرون.

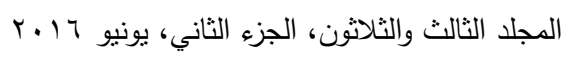


* نادية كاظم عنون العزاوي(Y l r): "تمكين المرأة الريفية في التنمية المستدامة في ريف محافظة بغداد".

استهدفت الدراسة التعرف على مستويات التمكين الاجتماعي والاقتصادي والسياسي والمهني للمرأة الريفية في التتمية المستدامة في ريف محافظة بغداد، وقد نم تحديد عينة الدراسة بطريقة عشوائية منتظمة وتم جمع البيانات بالمقابلة الثخصية للمبحوثات. وقد خلصت الدراسة إلى عدة نتائج أهمها أن غالبية المبحوثات في الفئة المتوسطة من حيث بـاني مستوى التمكين الاجتماعي حيث بلغت نسبتهن ع 1, 1 \% من المبحوثات. وأوضحت نتائج

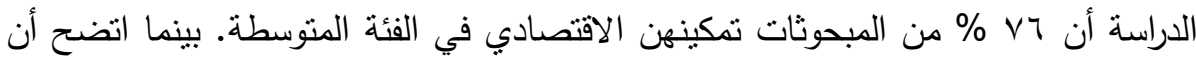
حوالي ب7 \% من المبحوثات مستوى التمكين السياسي لهن متوسط.

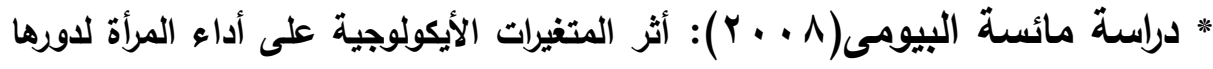
فى التنمية - دراسة أيكولوجية مقارنة بين منطقة عشوائية وأخرى حضرية.

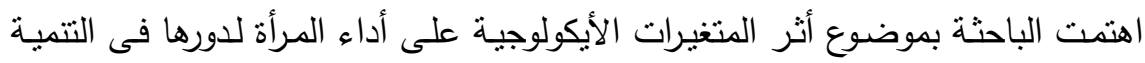

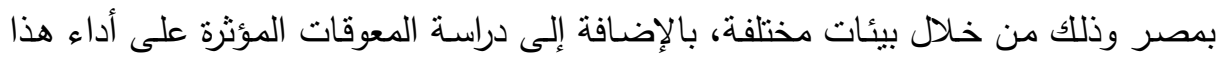
الدور • لذلك قامت الباحثة برصد واقع منطقة عشوائية مجاورة لمنطقة حضرية بمدينة القاهرة. وتوصلت الباحثة إلى عدة نتائج أهمها: تميز المنطقة الحضرية تعليمياً واقتصسادياً بالإضسافة

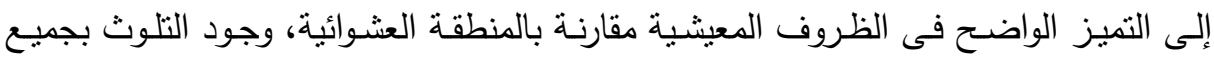
صوره وأثكاله فى المنطقتين، بالإضافة إلى تفاقم المشاكل البيئية فى المنطقة العشوائية. * دراسة هند مكى ( ( ץ): بعنوان "الثقافة الريفية ومشاركة المرأة فى التنمية دراسة سوسيولوجية مقارنة بين الريف والحضر بمحافظة سوهاج".

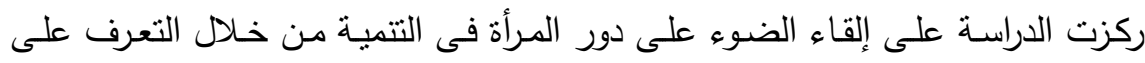

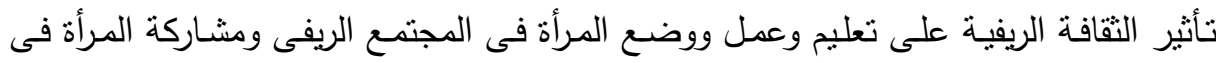

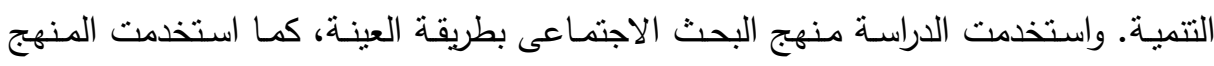

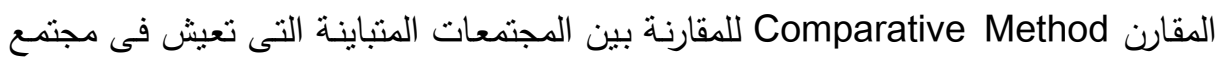
واحد لتوضيح أسباب الثبه والاختلاف بين هذه المجتمعات والجماعات. وتوصلت الدراسة من فن فئن 
خلال المعالجة الاحصائية على أن هناك علاقة قويـة بين المستوى التعليمى لمفردات عينة البحث ونوع الخلفة المفضلة سواء فى الريف أو الحضر ـ وكذلك مساهمة المرأة فى الأنشطة الاقتصادية والاجتماعية بمجتمع الدراسة.

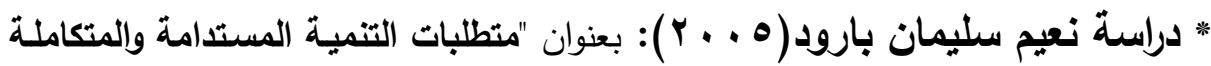
من المؤشرات الإحصائية"

وهدفت هذه الدراسة من خلال جمع وتحليل البيانات وعرضها ومقارنتها بدول أخرى إلى الى رفع مسنوى الوعى بين صانعى السياسات والمخططين، والمنظمات غير الحكومية، من أجل

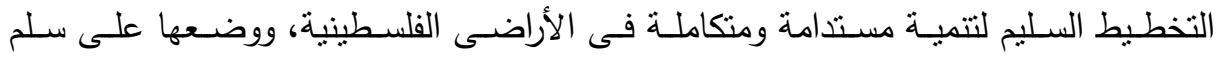
الأولويات من أجل تلبية الاحتباجات وضمان حياة آمنة وسليمة للمواطن الفلسطينى. وتوصلت الدراسـة إلى مجموعة من النتائج أبرزها: وجود تفاوت كبير فى معدلات التهات القراءة والكتابة بين

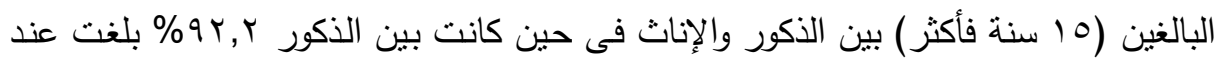

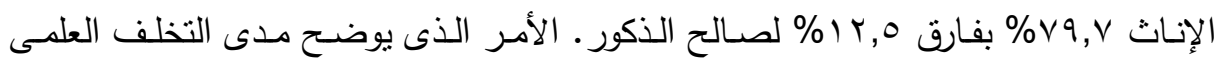

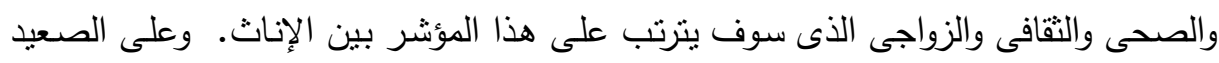

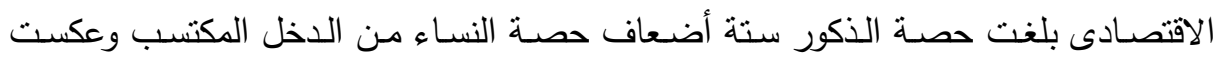
الإحصاءات كذلك تدنى مؤشر السكان الذين يحصلون على خدمات الصرف الصحى والتى إنى بلغت 9, 1 9\% الأمر الذى أدى إلى استخدام الحفر الامتصاصية والقنوات المكثوفة مما أدى

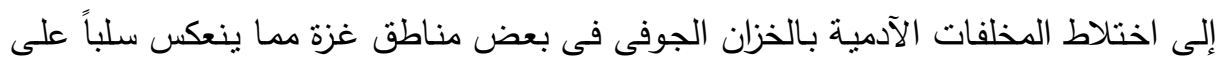
الحالة الصحية للسكان.

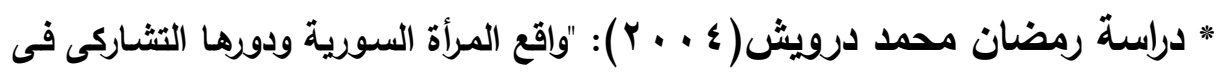
عملية التنمية".

استهدفت الدراسة تسليط الضوء على بعض جوانب تمكين المرأة السورية. وقد توصلت

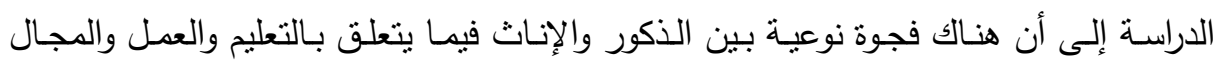

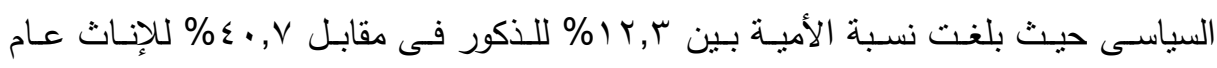

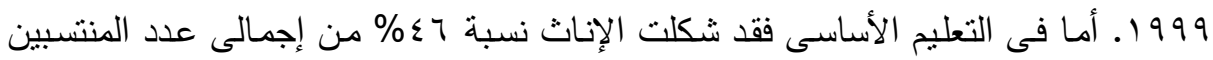

$$
\text { المجلا الثالث والثثلاثون، الجزء الثاني، يونيو } 17 \text { ـ ب r }
$$




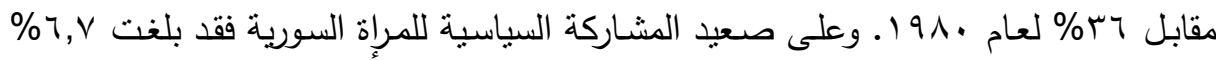

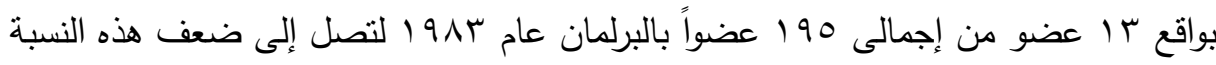

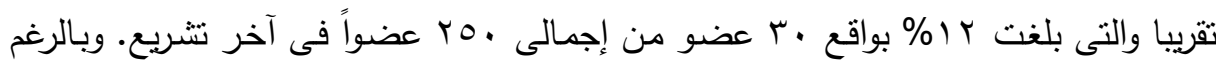

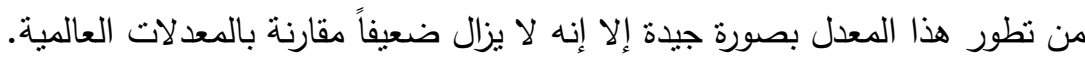

\section{الإطار اللزغريه}

أولاً: التنمية المستدامة:

الظروف الدولية التي أدت إلى ظهور فكرة التنمية المستدامة:

أدت مشاريع التتمية التى قام بها الإنسان فى مختلف النواحى الاقتصادية والاجتماعية والثقافية والسياسية إلى إحداث الكثير من التغيرات والإنجازات التى صاحبها الإضرار بالبيئة،

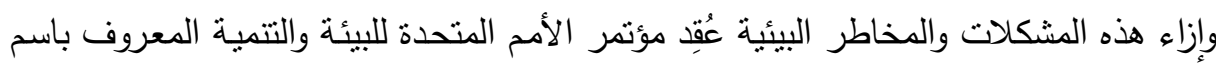

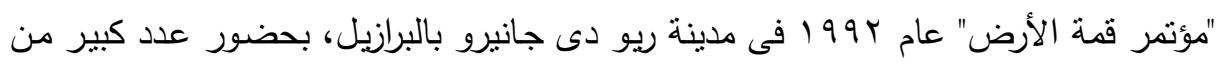

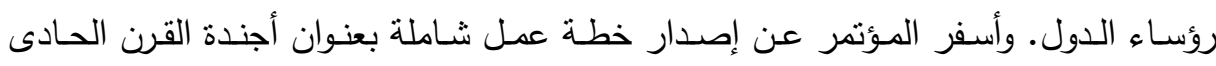

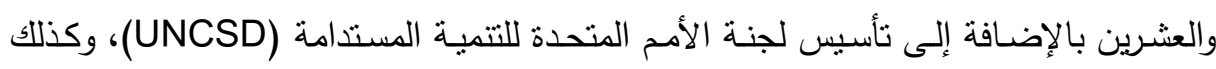

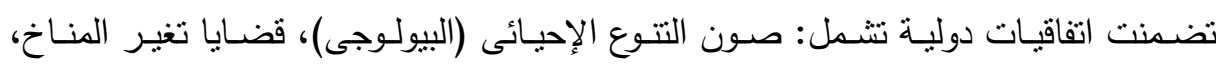

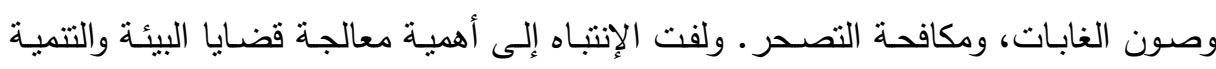
حفاظاً على مستقبل الإنسان، ومنه ظهرت فكرة التتمية المستدامة التى تحفظ حقوق الأجيال

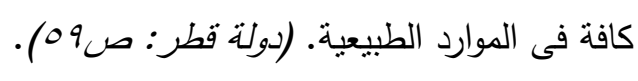
التظور التاريخى للتنمية المستدامة:

شهر مفهوم التنمية تطوراً كبيراً على مدى العصور المختلفة. فخلال عقدى الأربعينات

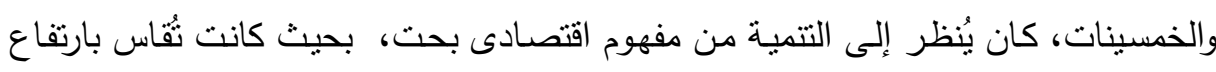

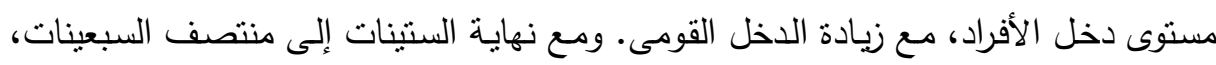

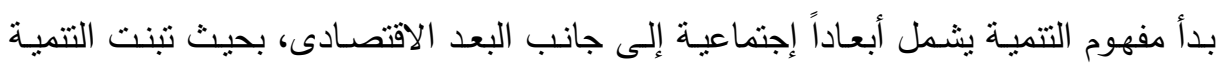

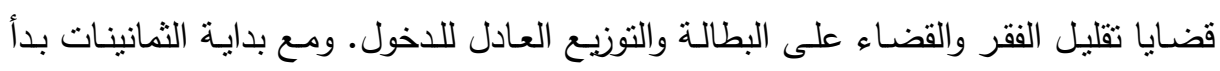


الظهور القوى والمؤثر لنموذج التتمية المستدامة الذى يحقق التوازن بين التتمية والبيئة، بين

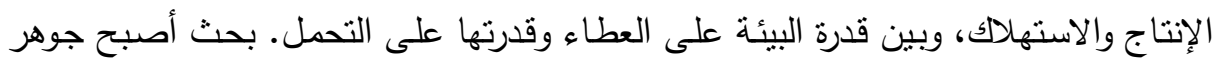
التتميـة المستدامة يتمثل فى كيفية تحقيق التتمية الاقتصادية والرفاهية الاجتماعية بأقل قدر ممكن من استهلاك الموارد الطبيعية وبالحد الأدنى من التلوث والإضرار بالبيئة. التعريفات المختلفة للتنمية المستدامة: تعريف لجنة برونتلاند 19 1 (اللجنة العالمبة للتنمبة المستدامة): "هى التتمية التى تلبى احتباجات الحاضر دون أن تُعرض للخطر قدرة الأجيال المقبلة

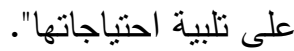

Sustainable development is development that "meets the needs of the present without compromising the ability of future generations to

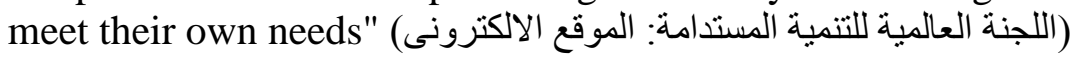

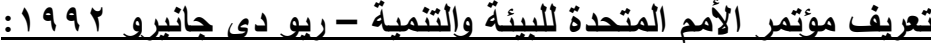

"إدارة الموارد الاقتصادية بطريقة تحافظ على الموارد والبيئة، أو تحسينها لكى تنمكن

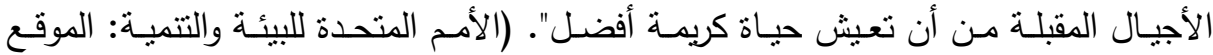

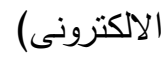

$$
\text { يمكن تلخيص هذه التعريفات فى التعريف التالى: }
$$

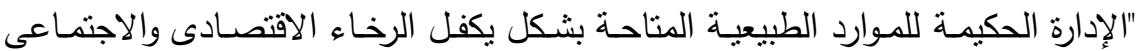

وتحقيق الاحتياجات الإنمائية والبيئية للأجبال الحالية والمقبلة".

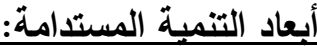

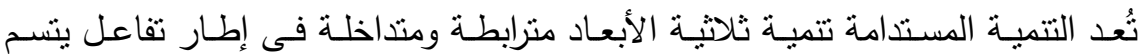

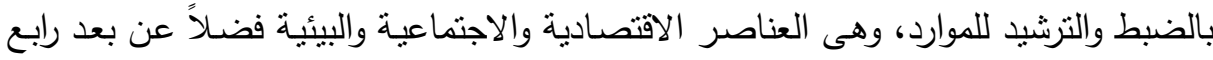

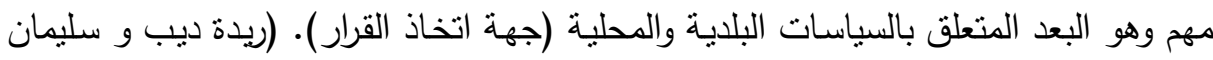

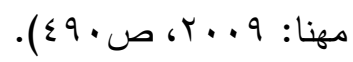




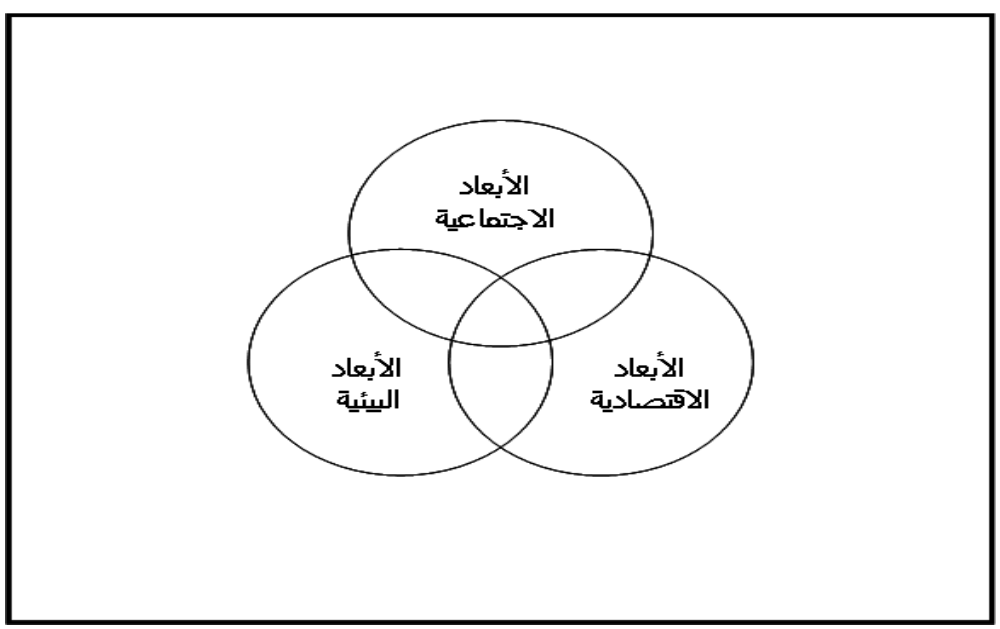

$$
\text { المصدر : (ريدة ديب رق (1): أبعاد التتمية المستدامة }
$$

أ. البعد البيئى للتنمية المستدامة: Environmental Dimension of Sustainability: وهو العمود الفقرى للتتمية المستدامة، وهو الاهتمام بإدارة المصادر الطبيعية. ب. البعد الاجتماعى للتنمية المستدامة: ونعزيز

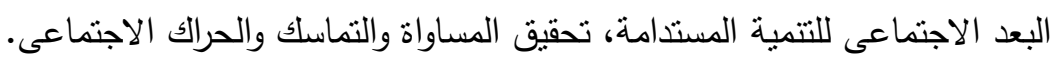

ج. البعد الاقتصادى للتنمية المستدامة: Economic Dimension of Sustainability: تحقيق أكبر قدر من العدالة فى توزيع الثروة. 


\section{ثُانياً: دور المرأة فى الحفاظ على البيئة:}

أصبحت مشاركة المرأة فى التتمية من أهم القضايا المعاصرة، وقد اهتمت الأمم المتحدة

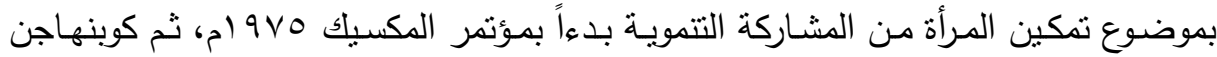

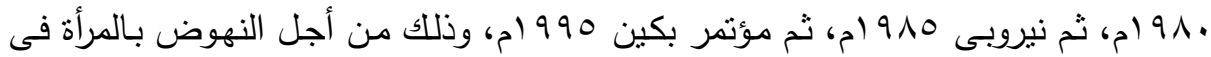

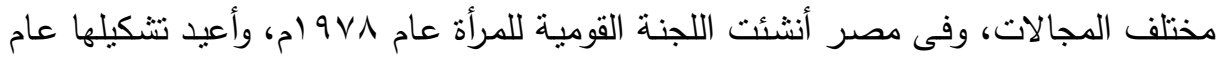
بو99 ام، وأخيراً أنثـئ المجلس القومى للمرأة عـام ... بام، وذلك بهدف النهوض بـالمرأة وتمكينها من المشاركة فى تفعيل التتمية المستدامة. ومن ثم فإن توجيه المزيد من الجهد نحو

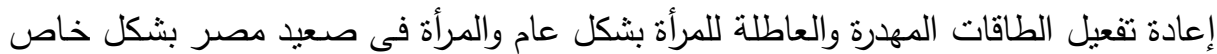
والاستفادة مـن قدراتها الإنتاجيـة والتوسـع فيها يعد شرطاً أساسياً لتحقيق التنميـة المستدامة

والمرأة الريفية فى الأسرة مسئولة عن حماية البيئة وخاصة البيئة المنزلية والداخلية فهى خط الدفاع الأول للحفاظ على صحة الأسرة من خلال تعليم وثقافة المرأة وزيادة وعيها بالبيئة حتى فى ظل محدودية الموارد التى يتصف بها الريف المصرى. ويظهر ذلك فى كيفية نقل المرأة للميـاه الصـالحة للشـرب، والحفـاظ عليهـا مـن التلوث، وكيفيـة تخزينهـا، وأيضـاً كيفيـة التخلص من المخلفات المنزلية بصورة صحية، وكيف يمكن لهذه المخلفات أن تعود بالنفع

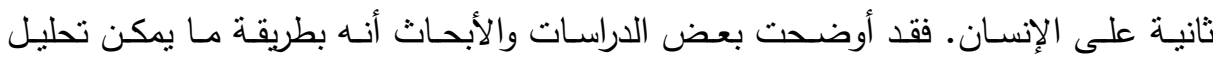
المخلفات المنزلية مع استبعاد المخلفات الصلبة كالزجاج والحديد. ويكون التحليل فى ظروف غير هوائية أى تحت التربة ويتم تخزينها فى براميل بلاستيكية، وبفعل الخمائر غير الهوائية

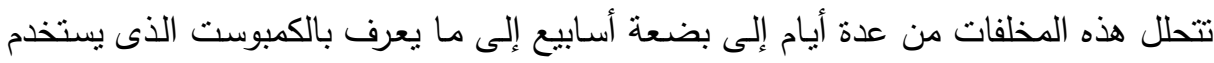

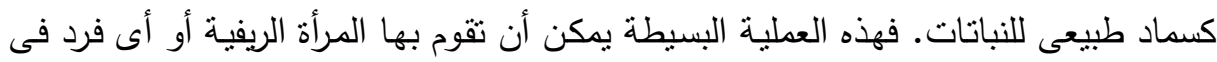

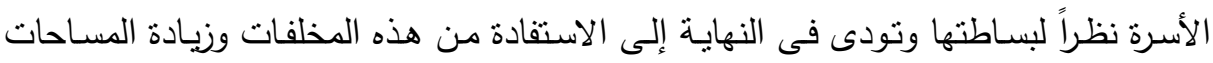
الخضراء وتقليل استخدام المبيدات الكيماوية. (عزيزة عبد الرازق السيد، ؟ . . ب) 
فعند تحليل السلوك البيئى للمرأة الريفية والتى هى محل الدراسة الحالية، نجد إنه يختلف

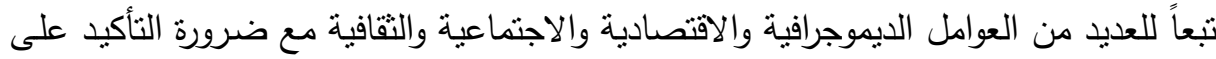
أهميـة دور المـرأة فـى الحفـاظ على البيئـة وصـيانتها باعنبارهـا عضـو نشــ فـى الأنشـطة

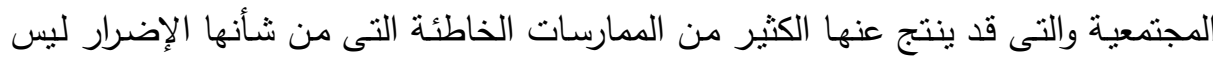

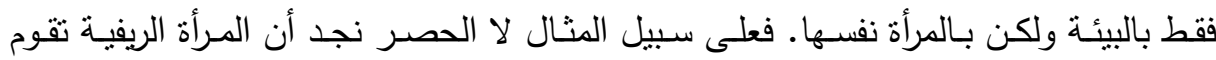

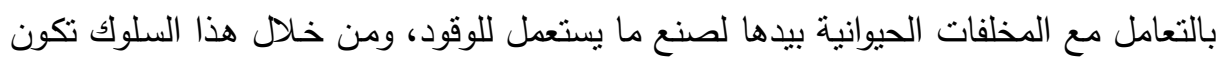

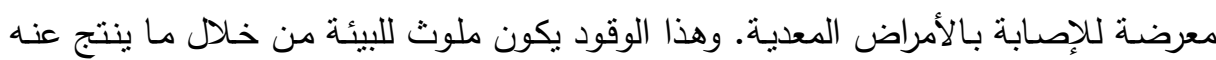

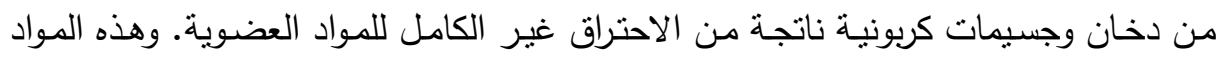

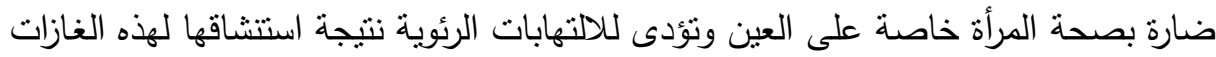
والأدخنة. وعليه تكون المرأة الريفية من أكثر الفئات تأثراً بالتدهور البيئى نظراً لتعدد مهامها لئها

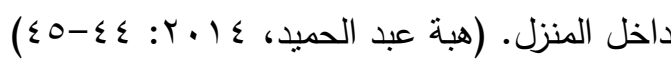

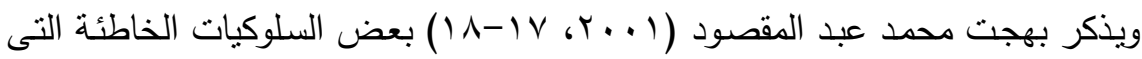
يشارك فيها الرجل والمرأة الريفيين بالإضافة إلى الأبناء تتمثل فى تلوث المياه نتيجة التخلص

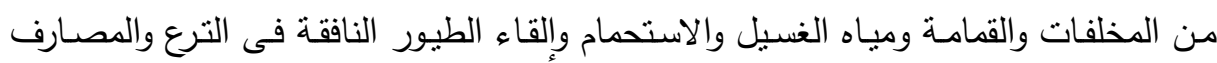

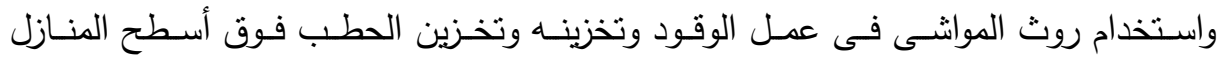
والإسراف فى استخدام المبيدات الحشرية داخل المنزل. ومن خلال هذه الممارسات التى من لهن شأنها الإضرار بالبيئة وبصحة الإنسان فقد يمكن لها أن تثق طريق آخر للنفع سواء بالبيئة أو أو هن

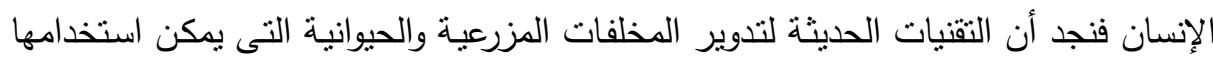

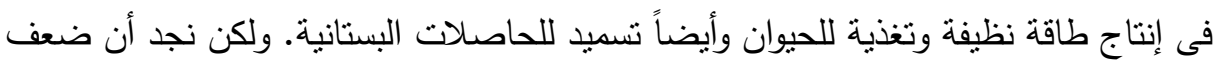
الوعى البيئى لدى الريفيات هو الذى يحول دون كفاءة تطبيق تلك التقنيات لذلك فهم فى حاجة

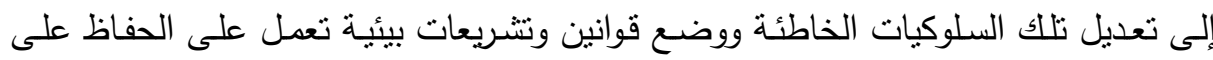




\section{اجزاءاهي الصراسمة}

للتحقق من صحة فروض الدراسة الحالية نم تتفيذ الاجراءات التالية: ( ) تصميم استمارة الاستبيان: من أجل تحقيق أهداف الدراسة الحالية، تم قياس مدى مساهمة المرأة فى الحفاظ على البيئة من خلال مجموعة من العبارات اثثين وثلاثثين عبارة تتنمل فى مضمونها مجموعة من معارف وسلوكيات المرأة الريفية فى الحفاظ على البيئة الريفية، وكانت الاستجابة عن كل عبارة نتعلق بمعرفة المرأة من عدمها عن البيئة

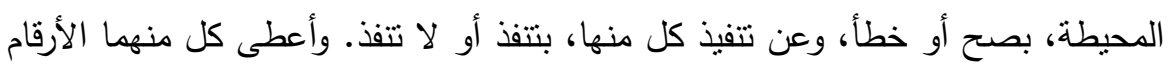

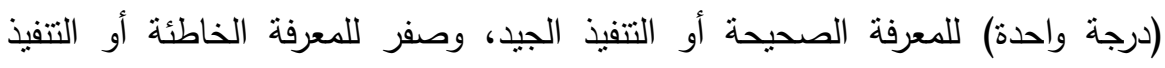
الخاطئ. ثم تم جمع هذه الدرجات جبرياً لتكوين متغير دور المرأة فى الحفاظ على البيئة.

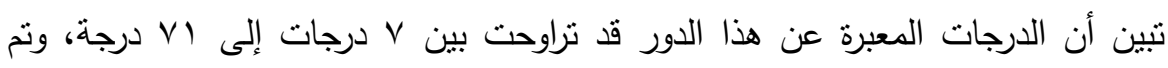
تقسيم هذا المتغير إلى ثلاث مستويات من المساهمة (منخفضة، منوسطة، ومرتفعة). وتضمنت عبارات قياس متغير "دور المرأة فى الحفاظ على البيئة" المحاور التالية:

$$
\begin{aligned}
& \text { () الحفاظ على التربة الزراعية، ويتضمن أربع عبارات. } \\
& \text { r) استخدام المبيدات الحشرية، ويتضمن أربع عبارات. }
\end{aligned}
$$

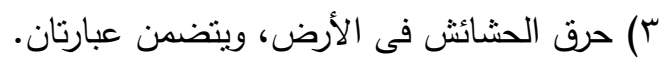

$$
\begin{aligned}
& \text { ع) استخدام الأسمدة الكيماوية، ويتضمن أربع عبارات. } \\
& \text { 0) الحفاظ على الماء، ويتضمن سبع عبارات. } \\
& \text { ج) الحفاظ على الهواء، ويتضمن ست عبارات. } \\
& \text { (V النظافة والصحة العامة، ويتضمن خمس عبارات. }
\end{aligned}
$$

ثبات وصدق الاستبيان: نم التحقق من صدق الاستبيان بعرضهـ على مجموعة من المحكمين

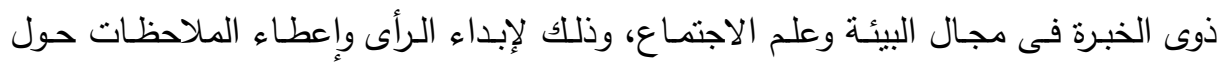
مفردات الاستنيان، مـن حيث مدى مناسبة محتواهـا وانتمـاء فقراتها لمجالاتها، وتم تعديل الاستبيان فى ضوء هذه الملاحظات. 
ونظراً لصعوبة تحقيق الثبات والصدق بأسلوب إعادة الاختبار (test-retest)، لجأت الباحثة لتحقيق ثبات الاستبيان إلى الخطوات التالية:

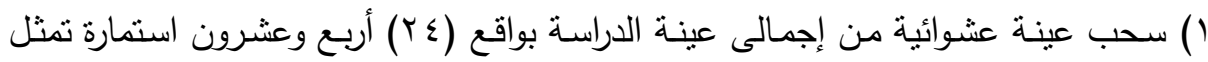
المبحوثات، واعنبارها كعينة مستقلة قوامها ع ب سيدة.

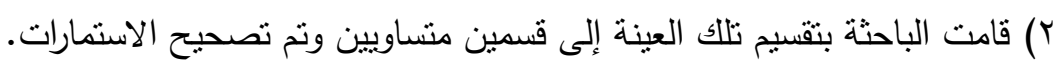

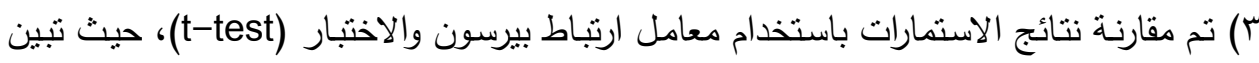
ارتفاع معاملات الارتباط بين العينتين مما يشير إلى معاملات ثبات جيدة (مV0, · · ). جدول رقم(1): التوزيع النسبى والعددى للمبحوثات وفقاً لدورهن فى الحفاظ على البيئة

\begin{tabular}{|c|c|c|}
\hline$\%$ & العدد & الفئة \\
\hline$r, 1$ & $\mathrm{~V}$ & من V-V r (دور منخفض) \\
\hline$\sum \vee, T$ & $1 \cdot V$ & من ·r- 0 (دور متوسط) \\
\hline$\varepsilon 9, r$ & 111 & من إ- VI (دور مرتفع) \\
\hline $1 \ldots$ & TYO & المجموع \\
\hline
\end{tabular}

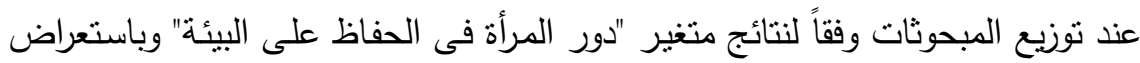

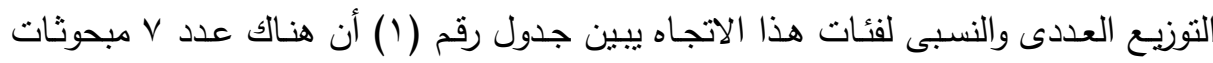

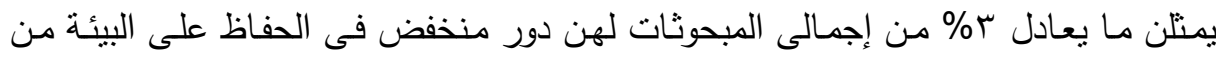

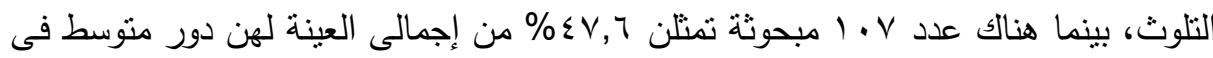

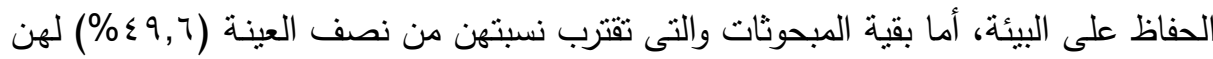
دور مرتفع فى الحفاظ على البيئة.

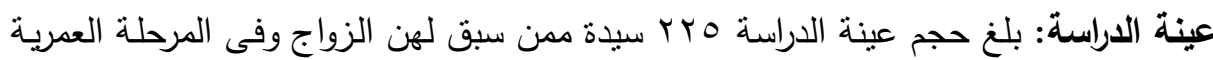
1 19 §، والمقيمات بقرية شوشـة بمركز سمالوط بمحافظة المنيا. وتم اختيار العينة بطريقة

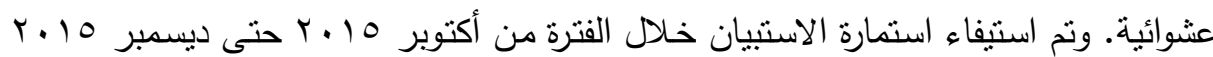
عن طريق المقابلة الثخصية مع المبحوثات. 


\section{نيتائي الصراسة}

\section{1 - الارتباط بين المتفيرات المستقلة ودور المرأة فى الحفاظ على البيئة:}

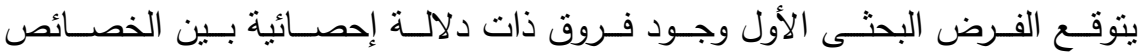

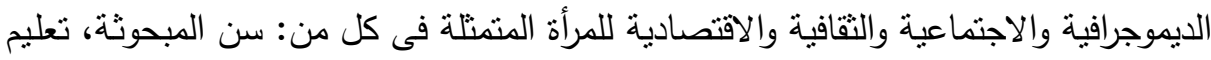

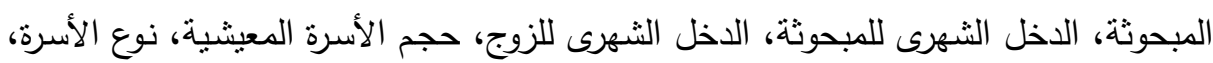

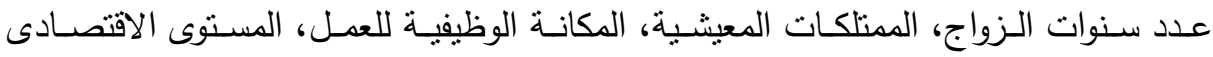

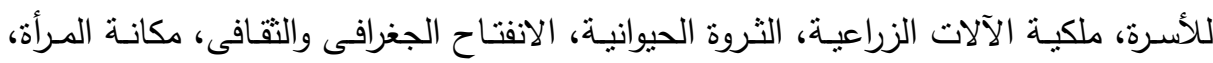
نوعية المسكن، ودورها فى الحفاظ على البيئة كأحد محاور التتمية البيئية المستدامة.

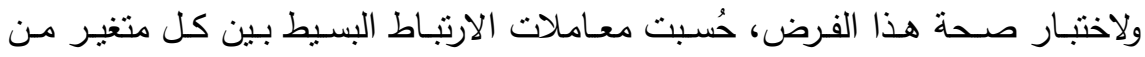

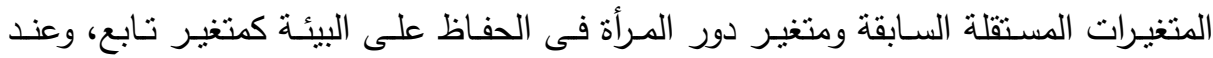

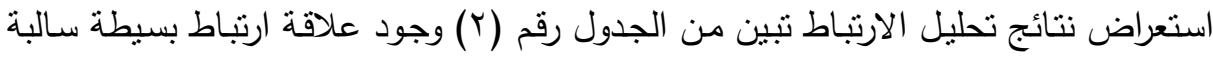

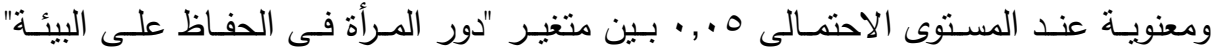

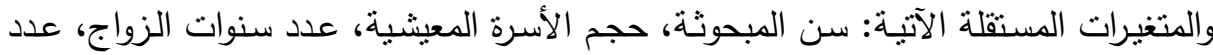

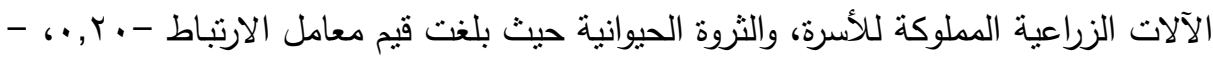
海 جدول رقم(ץ): نتائج نحليل الارتباط بين المتغيرات المستقلة والمتغير التابع (دور المرأة فى النى الحفاظ على البيئة)

\begin{tabular}{|c|c|c|c|c|c|}
\hline الارتباط & المتغيرات المستقلة & b & معامل الارتباط & المتغيرات المستقلة & م \\
\hline$\cdot, r V \varepsilon-$ & ملكية الآلات الزراعية & 9 & $\because, \cdot r \cdot-$ & سن المبحوثة & 1 \\
\hline$\cdot, \cdot Y q$ & المكانة الوظيفية للعمث & 1. & $\because, r \cdot q$ & تعليج المبحوثة & r \\
\hline$., 1,1$ & المستوى الآقتصنادى للأَسرة & 11 & $\cdot, 1 \leqslant 7$ & دخل المبحوثة & $r$ \\
\hline$\cdot, 1 \cdot Y$ & مكانة المرأة & $\overline{T Y}$ & $\cdot, 1 \%$ & دخل الزوج & $\varepsilon$ \\
\hline$\cdot, \varepsilon \vee \vee-$ & الثروة الحيوانية & $\pi$ & $\cdot, 1 Y \wedge-$ & حجم الأسرة المعيشياً & \\
\hline$\because, .70$ & الانفتاح الجغرافى والثنقافى & $1 \varepsilon$ & $\cdot, \cdot v \cdot-7$ & نوع الأسرة & 7 \\
\hline$\cdot, .71$ & نوعية المسكن & 10 & $\cdot, \cdot 7 \lambda-$ & عدد سنوات الزواج & $\bar{v}$ \\
\hline & & & $\cdot,, \leqslant 0$ & الممنلكات المعيشية & 入 \\
\hline
\end{tabular}


حيث تثير تلك النتائج أن متغير السن يمثل علاقة عكسية بالنسبة للحفاظ على البيئة، فنجد أن المرأة المتقدمة فى السن والتى غالباً ما تكون أمية يكون اتجاهها سالب نحو حماية انسية

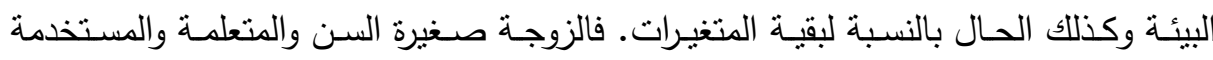

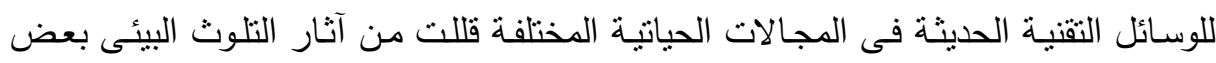
الثـئ بالرغم من تضرر البيئة من المخلفات الكيميائية والإشعاعية المختلفة إلا إنه غير من لهنه

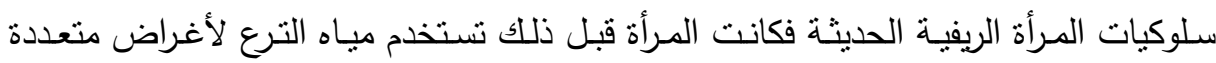

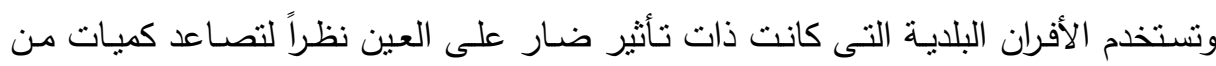
الرصاص ناتجة عن احتراق الوقود والذى يؤثز بدوره على نقاء الهواء.

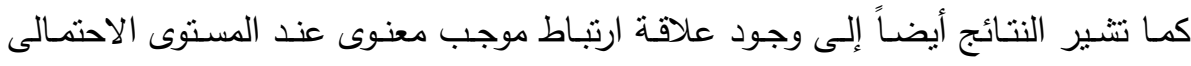
ه . , • بين متغير دور المرأة فى الحفاظ على البيئة كمتغير تابع وبين المتغيرات المستقلة الآتية:

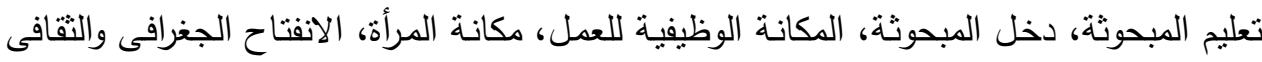

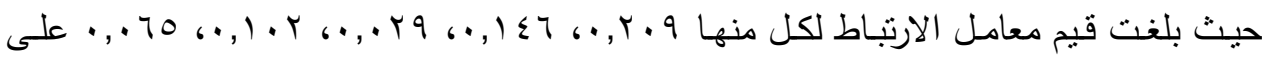
الترتيب.

وتعكس هذه النتائج وجود علاقة طردية بين مقدار تعليم المبحوثة وبين سلوكياتها فى ري

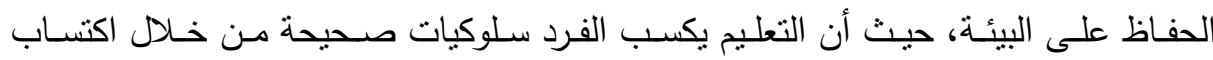
المعارف والقيم الإيجابية، وأيضاً دخل المبحوثة حيث أن المستوى الاقتصادى المناسب بكان يمكن

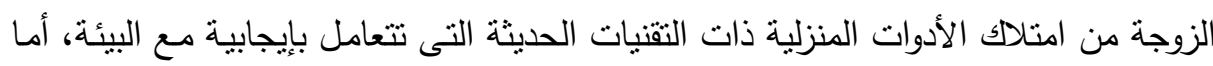

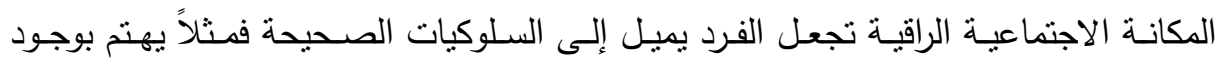
مساحات خضراء ونظيفة سواء داخل أو خارج المنزل، وكذلك المكانة الوظيفية للعمل، فالمرأة التى تعمل تكتسب خبرات وتقنيات حديثة للسلوكيات البيئية سواء بأماكن العمل أو المنزل، أما وكاء

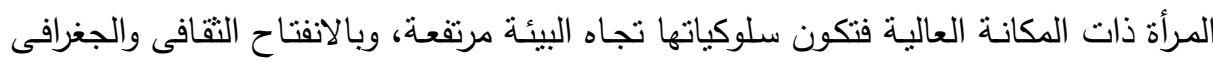
تكتسب المرأة المعلومات والمهارات البيئية الصحيحة. 


\section{r - محددات دور المرأة فى الحفاظ على البيئة:}

يتوفع الفرض البحثى الثنانى أن يسهم كل متغير من المتغيرات المستقلة الثالية: سن المبحوثـة، تعليم المبحوثـة، الدخل الثــهرى للمبحوثـة، الدخل الثـهـرى للزوج، حجم الأسـرة

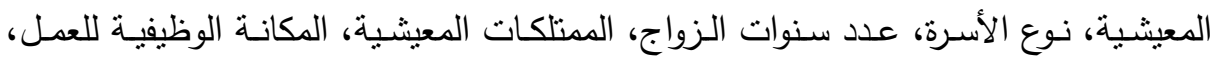

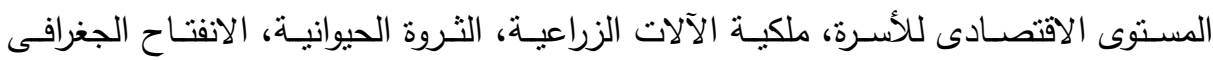

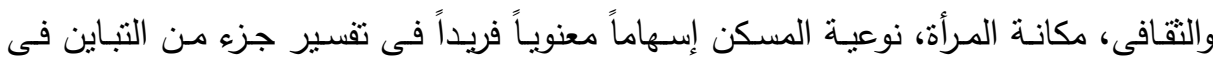

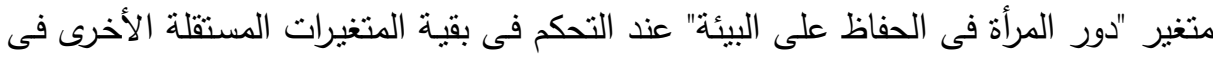
النموذج التحليلى. ولاختبار صحة هذا الفرض، تم الاستعانة بأسلوب الانحدار الخطى المتعدد التدرجى الصاعد Stepwise Multiple Regression للوقوف على محددات دور المرأة فى الحفاظ على البيئة، والتعرف على الأهمية النسبية لكل متغير معنوى، ومقدار تفسير كل متغير فى شرح جزء من التباين فى المتغير التابع (دور المرأة فى الحفاظ على البيئة).

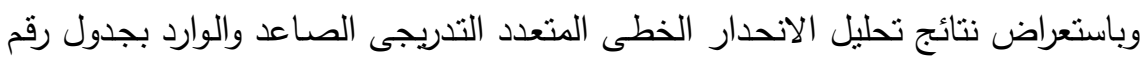
(T) تبين أن هناك ست متغيرات فقط من إجمالى خمسـة عشر متغيراً مستقلاً نسـهم إسهاماً معنوياً فريداً unique contribution فى تفسير درجات التباين فى متغير "دور المرأة فى إنى

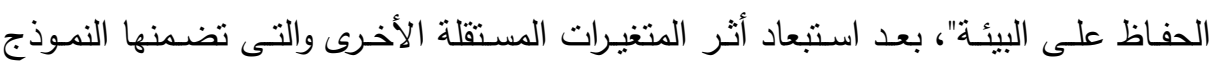

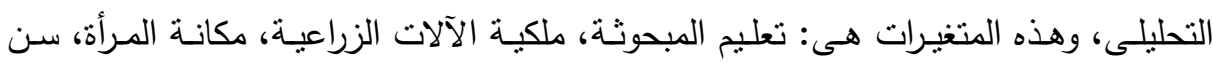
المبحوثة، الانفتاح الجغرافى والثقافى، المكانة الوظيفية للعمل.

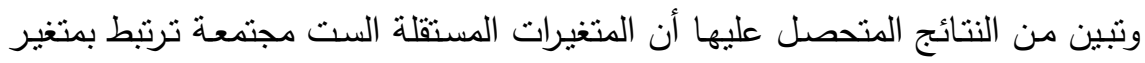

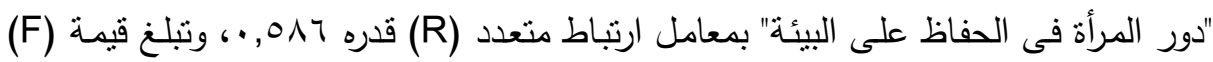

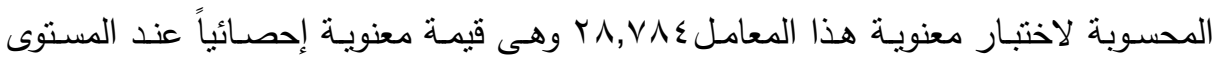

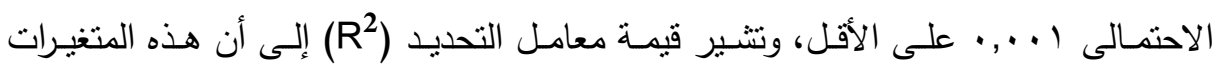
المستقلة تفسر نحو ع,؟؟\% من التباين فى درجات دور المرأة فى الحفاظ على البيئة، بينما تتسب العوامل المتبقية الأخرى من التباين إلى عوامل أخرى لم يتضمنها النموذج التحليلى.

$$
\text { المجلا الثالث والثلاثثو، الجزء الثاني، يونيو } 17 \text { ـ ب r }
$$


وعلى أية حال فإن هذه النتيجة تؤيد جزئياً الفرض البحثى الخاص بدور المرأة فى الحفاظ على البيئة.

وعند الوقوف على نسبة إسـهام كل متغير من المتغيرات المستقلة المعنويـة فى تفسبر

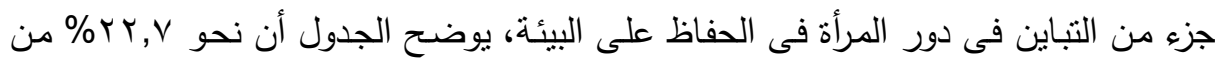

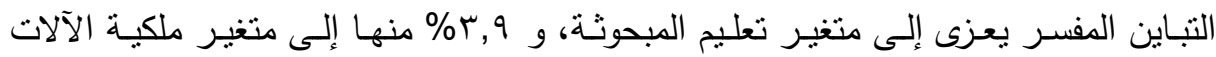

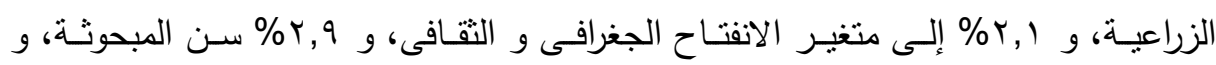

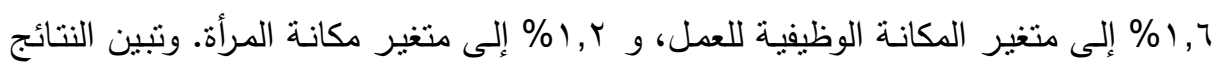

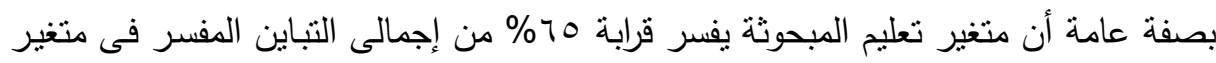
دور المرأة فى الحفاظ على البيئة. أما عند استعراض الأهمية النسبية لكل متغير من المتغيرات المستقلة المعنوية بالتحكم فى باقى المتغيرات المستقلة المعنويـة الأخرى، فقد تبين من قيم معاملات الانحدار الجزئية

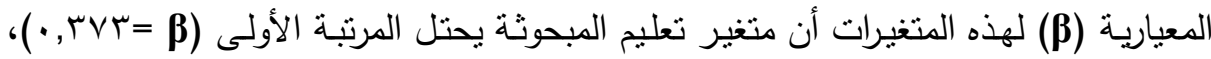

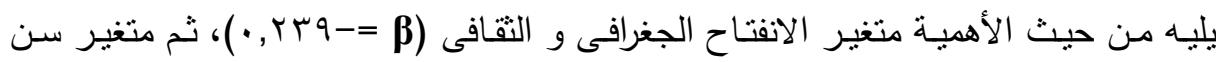

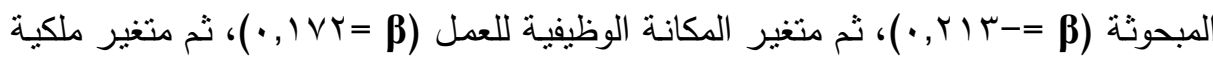

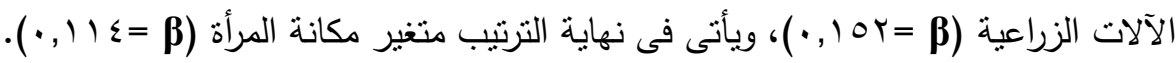


جدول رقم(ץ): نتائج تحليل الانفتاح الجغرافى و النقافى الانحدار الخطى المتعدد التدرجى الصاعد للعلاقة بين المتغيرات المستقلة ذات الإسهام المعنوى والفريد و "دور الإن المرأة فى الحفاظ على البيئة"

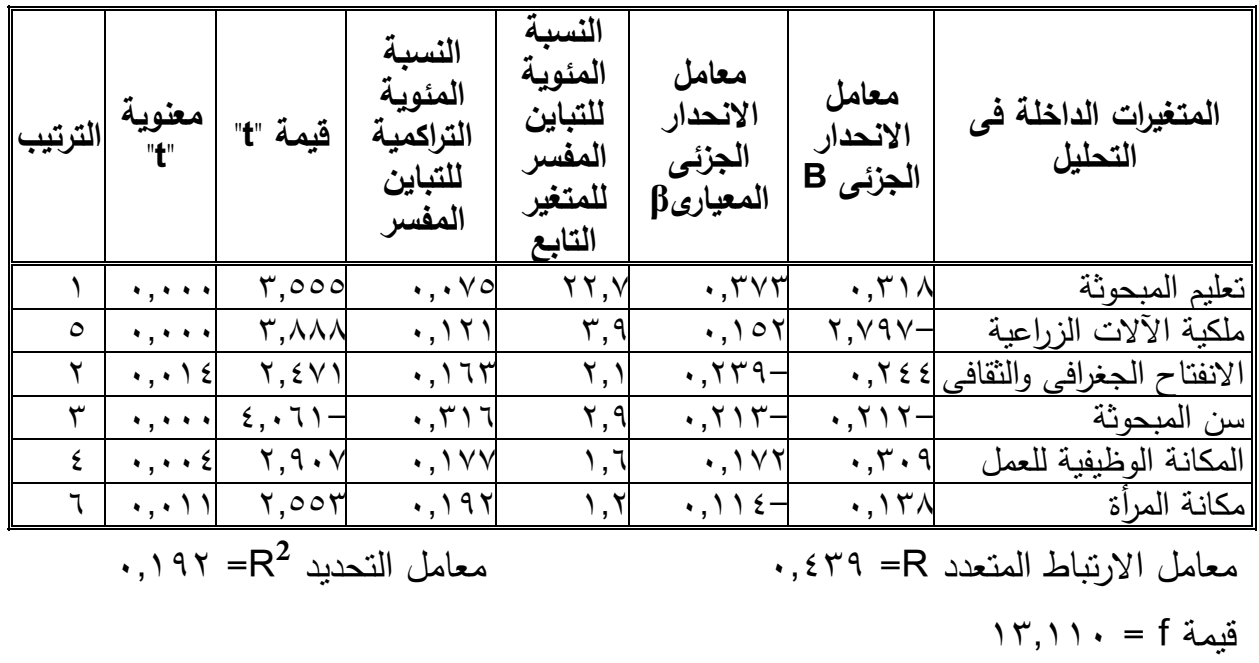

وتثتير تللك النتائج إلى أن المتغيرات سالفة الذكر تُعد مؤثرات هامة لتفعيل دور المرأة فى الحفاظ على البيئة، حيث يؤثر كل من السن ودرجة الانفتاح الجغرافى والثقافى تأثنيراً عكسياً

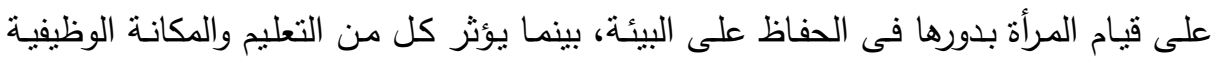

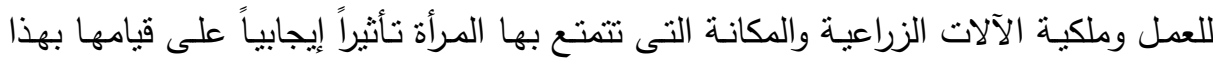

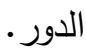

\section{اللموصياهت}

• توعية المرأة بمفهوم التتمية المستدامة ومساراتها وطرق ترسيخ مبدأ شراكة المرأة فى تفعيل

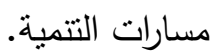
• تفعيل دور المؤسسـات التعليميـة والتربويـة من خـلال منـاهج دراسية دقيقة ترسـخ مبـادئ التتمية البيئية المستدامة بالإضافة إلى تفعيل دور المؤسسات الدينية والمساجد . • إدمـاج المرأة في جميع الأنشطة التتمويـة ومشـاركتها في إدارة الموارد الطبيعيـة وإناحـة الفرصة للوصول إلى المراكز القيادية. 


$$
\begin{aligned}
& \text { • العمل على سد منابع الأمية والنهوض بمحو الأمية. } \\
& \text { • اعداد برامج لتعزيز الوعي الاستهلاكي المستدام للمرأة. }
\end{aligned}
$$

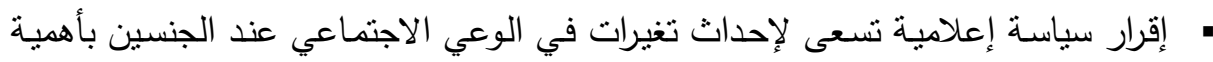

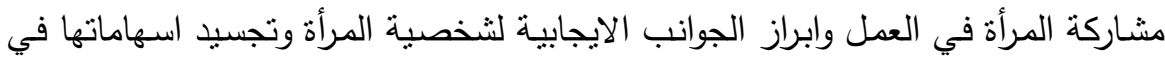
• ت تشجيع المرأة على المشاركة فى الأنشطة المجتمعية والسياسية.

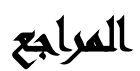

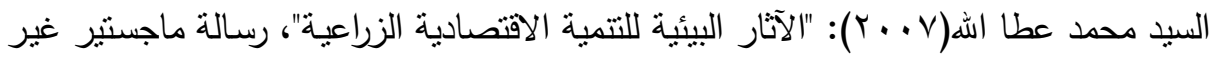
منشورة، كلية الزراعة، جامعة كفر الثيخ الثاري

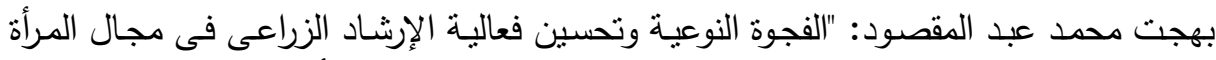

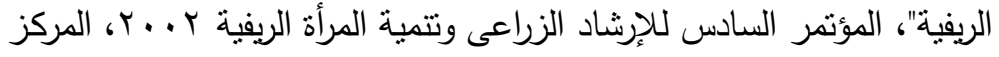

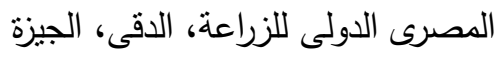

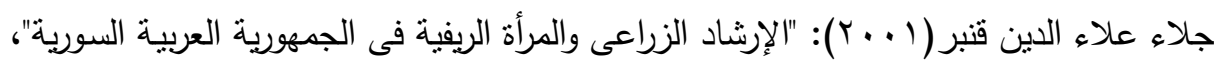

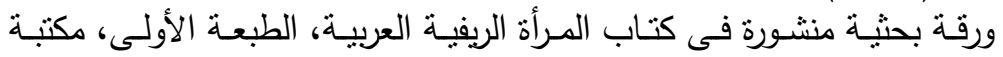

$$
\text { ومطبعة الإشعاع الفنية. الإسكندرية }
$$

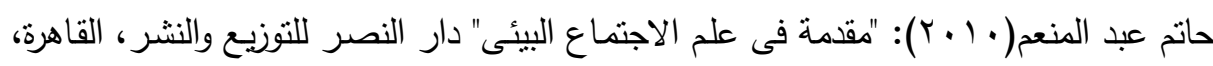

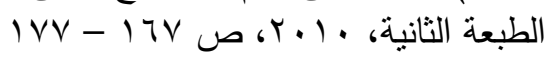

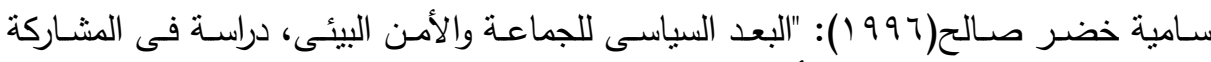

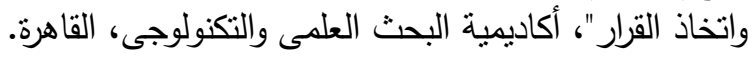

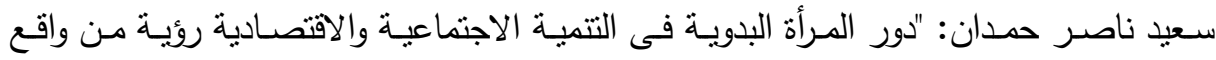

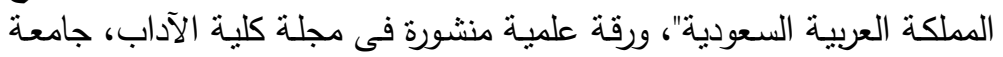

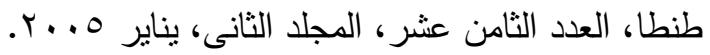




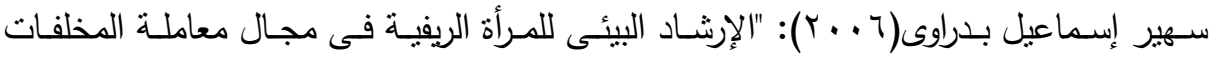

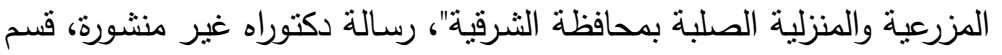
الإرشاد الزراعى، كلية الزراعة، جامعة عين شمس الفس الفرة

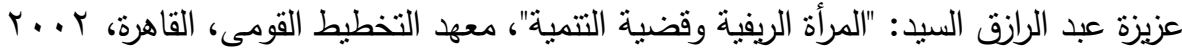

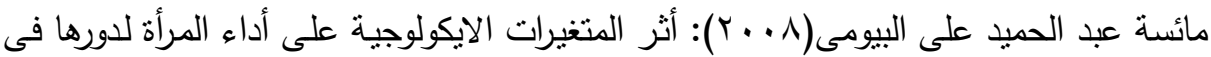

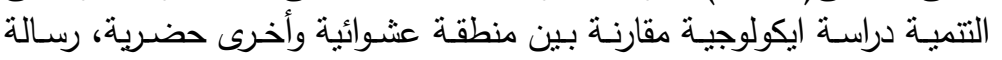

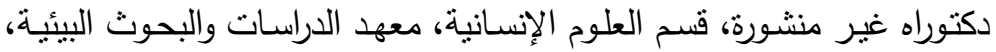
جامعة عين شمس فيز منسر

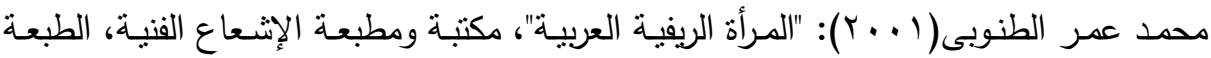

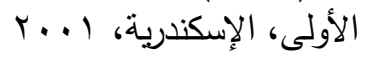

معن خليل عمر (ـ 99 ()): "علم اجتماع الأسرة"، دار الثـروق للنشر والتوزيع، عمان، الطبعة

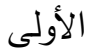

نادية كاظم عنون العزاوي(r ( • Y): "تمكين المرأة الريفية في التتمية المستدامة في ريف محافظة

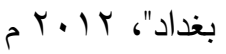

نعيم بارود سليمان: "متطلبات التتمية المستدامة المتكاملة من المؤشرات الإحصـائية"، الجامعة

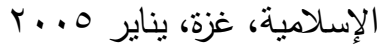

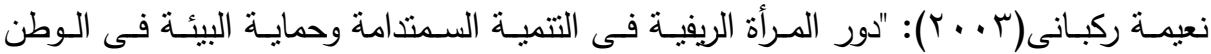

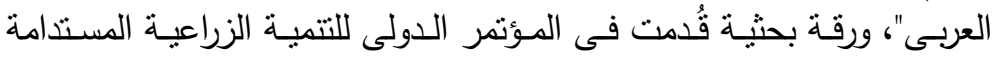

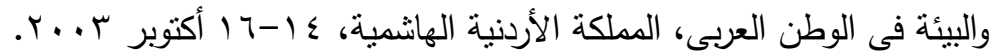

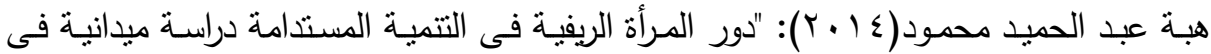
محافظة كفر الثيخ"، رسالة ماجستير غير منشورة، كلية الزراعة، جامعة كفر

$$
\text { الثيخ. }
$$

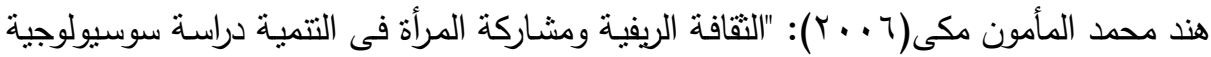
مقارنة بين الريف والحضر بمحافظة سوهاج"، رسالة ماجستير غير منشورة، الإنة

$$
\text { كلية الآداب، قسم الاجتماع، جامعة أسيوط }
$$

Johnson A., (1995): “The Blackwell Dictionary of Sociology, A User's Guide to sociological Language" ", Bleach Well Publishers Inc., 1st ed., U. S. A.

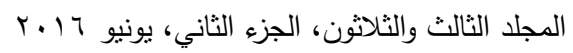


Johnson D. \& Johnson F. P., (1991): "Joining Together Group Theory Media and Group Skills", Prentice Hall International, Inc., U. S. A.

United Nations for Environment and Development (1992): www.uned.org

World Commission On Environment And Development (1987): “Our Common Future", Oxford University Press, Geneva, Switzerland.

\title{
DETERMINANTS OF THE ROLE OF WOMAN IN ENVIRONMENTAL SUSTAINABLE DEVELOPMENT
}

\author{
Saleh, Samia, Kh. ${ }^{(1)}$; Abdelmoneem, A. M. ${ }^{(2)}$ \\ and Attiya, Randa, $\mathrm{H}^{\left({ }^{(3)}\right.}$
}

1) Faculty of Education, Ain Shams University 2) League of Arab States 3) Ministry of Education

\begin{abstract}
The present study aimed at identifying the role of woman in environmental sustainable development "environmental conservation" in one village at Minia Governorate, and identifying the main significant socio-economic, demographic and cultural correlates and determinants of the role of woman in environmental sustainable development and their relative importance.

A random sample of 225 women was selected from shosha village in El-Minia governorate. An interview questionnaire was and designed to include various variables pertained to the objectives of the study. It was pre-tested and modified accordingly. Percentages, standard deviation, zero-order

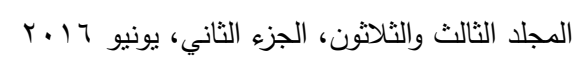


سامية خضر صالح وآخرون

correlation, and Step-wise multiple regression (forward solution) techniques were the tools of data analysis.

Step-wise multiple regression analysis showed that, six independent variables out of the fifteen independent variables made a significant unique contribution to regression equation. The six independent variables taken together explain about $34.4 \%$ of the total variance of environmental conservation. These six variables are: Educational Status; ownership of agricultural equipments; Respondent' age; cultural and geographical openness; Work status and Women's empowerment.

The study recommended that more effort need to be provided such as: provision of reproductive health services, provide more job opportunities for women, in addition to providing more educational opportunities, especially for women in rural and disadvantaged areas in order to empower women to achieve sustainable development in the governorate. 